\title{
Componentes não-integrantes da carcaça de bovinos de três grupos genéticos terminados em confinamento ou pastejo rotacionado com suplementação
}

\author{
Non-carcass components of three genetic beef cattle group finished in feedlot or \\ rotational grazing with supplementation
}

\section{PERIPOLLI, Vanessa ${ }^{*}$; BARCELLOS, Júlio Otávio Jardim² ${ }^{2}$ OLMEDO, Diego Avilio Ocampos $^{2}$; LAMPERT, Vinícius do Nascimento ${ }^{3}$; VELHO, Maria Martha Silva ${ }^{4}$}

\author{
${ }^{1}$ Universidade Federal do Rio Grande do Sul, Faculdade de Agronomia, Departamento de Zootecnia, \\ Porto Alegre, Rio Grande do Sul, Brasil. \\ ${ }^{2}$ Universidad Nacional de Asunción, Facultad de Ciencias Agrarias, Asunción, Paraguai. \\ ${ }^{3}$ Embrapa Pecuária Sul, Bagé, Rio Grande do Sul, Brasil. \\ ${ }^{4}$ Agronoma, Autônoma, Palmeira das Missões, Rio Grande do Sul, Brasil. \\ *Endereço para correspondência: vanessa.peripolli@ hotmail.com
}

\section{RESUMO}

Foram avaliados os componentes nãointegrantes da carcaça de bovinos castrados (novilhos) Brahman, Brangus e Hereford terminados em confinamento ou pastejo com suplementação (capim-mombaça). Os animais foram abatidos com espessura de gordura subcutânea superior a $4 \mathrm{~mm}$. A dieta do confinamento foi formulada com $60 \%$ de volumoso e $40 \%$ de concentrado, com $13 \%$ PB e $62 \%$ NDT. O capim mombaça apresentou $7 \%$ de PB e 56\%NDT e o suplemento apresentou $24 \%$ PB e $76 \%$ NDT. O delineamento experimental foi inteiramente casualizado, com arranjo fatorial $3 \times 2$ (três grupos genéticos e dois sistemas de terminação) e as médias foram comparadas pelo teste de Tukey ajustado. Foram observadas diferenças significativas para o peso de abate (PA) e peso do corpo vazio (PCV) favorável aos animais mantidos em pastejo com suplementação $(444,03$ vs $416,50 \mathrm{~kg}$ para PA e 409,68 vs $375,24 \mathrm{~kg}$ para $\mathrm{PCV})$, entretanto não houve diferença significativa entre os sistemas de terminação para o rendimento de corpo vazio (RCV). O menor percentual de órgãos vitais foi apresentado pela raça Brahman independente do sistema de terminação utilizado (2,19\%). A mesma tendência foi observada para o trato digestivo com um percentual de participação de $3,77 \%$ PCV do Brahman vs $4,87 \%$ e $4,48 \%$ PCV do Hereford e Brangus, respectivamente. Os novilhos Brahman apresentaram menores pesos de coração, pulmão e baço que os Hereford e Brangus. Os animais terminados em pastejo apresentaram maiores pesos de abomaso, pulmão e rins que os terminados em confinamento, 0,47 vs $0,35 \%$ PCV; 0,77 vs $0,71 \%$ PCV e 0,77 vs $0,71 \%$ PCV, respectivamente.

Palavras-chave: componentes externos, couro, fígado, gordura, trato digestivo.

\section{SUMMARY}

The non-carcass components of steers from Brahman, Brangus and Hereford finished in feedlot or pasture with supplementation (mombaça grass) were evaluated. The animals were finished when subcutaneous fat thickness was over $4 \mathrm{~mm}$. The feedlot diets have roughage:concentrate ratio of 60 : 40 , with $13 \%$ $\mathrm{CP}$ crude protein and $62 \%$ TDN. The level of $\mathrm{CP}$ of mombaça grass was $7 \%$ with $56 \%$ TDN, and the supplement was $24 \% \mathrm{CP}$ and $76 \% \mathrm{TDN}$. The experimental design was completely randomized with a $3 \times 2$ factorial arrangement (three genetic groups and two finishing systems) and means was compared by adjust Tukey test. Significant difference was observed for the slaughter weight (SW) and empty body weight (EBW) in steers maintained at pasture with supplementation. (409.68 versus $375.24 \mathrm{~kg}$ of empty body weight), however, no differences were observed with the percentage of empty 
body dressing percentage (EBD). Brahman steers has the lowest percentage of vital organs independent of finishing system $(2.19 \%)$. Same trend was showed for the total empty digestive tract with $3.77 \%$ for Brahman steers vs 4.87 and $4.48 \%$ EBW of Hereford and Brangus. The Brahman steers had lower weights of heart, lung and spleen than the Hereford and Brangus. Animals finished on pasture had greater weight of abomasums lung and kidneys than animals finished on feedlot 0.47 vs $0.35 \% \mathrm{EBW} ; 0.77$ vs $0.71 \%$ EBW and 0.77 vs $0.71 \%$ EBW, respectively.

Keywords: external components, fat, gut, leather, liver.

\section{INTRODUÇÃO}

A produção de carne bovina nas regiões tropicais é oriunda de diferentes sistemas de terminação e de um rebanho que se caracteriza por uma composição genética variada. Junto com a valorização da carne a quantificação das partes do corpo vazio não-integrantes da carcaça torna-se importante devido a sua valorização pela indústria e principalmente pela sua associação ao rendimento de carcaça (KUSS et al., 2008; CATTELAM et al., 2011).

A avaliação dos componentes do corpo vazio não-integrantes da carcaça pode ser valiosa para o entendimento das características relacionadas ao desempenho e a carcaça dos animais. Neste sentido, uma implicação prática é a relação com as exigências energéticas dos animais, especialmente a de mantença. Estudos apontam uma relação negativa entre os componentes externos e trato digestivo com o rendimento de carcaça (VAZ et al., 2001; SANTOS et al., 2003a; KUSS et al., 2008; CATTELAM et al., 2011) e que animais com maiores pesos de órgãos vitais, principalmente fígado, e maior acúmulo de gordura interna são energeticamente mais exigentes (FERREL\& JENKINS,
1998). Também, existe associação entre o tamanho e a atividade metabólica presente nos tecidos dos órgãos vitais e as maiores exigências energéticas de mantença (SOLIS et al., 1988; CALEGARE et al., 2007).

A interação do genótipo- ambiente também influencia as exigências de mantença dos animais. Tedeschi et al. (2002) sugerem que os desempenhos dos Bos indicus com relação aos Bos taurus são, no mínimo, iguais em condições nutricionais limitantes. Segundo Chizzotti et al. (2007), os animais produtos dos cruzamentos Bos indicus-Bos taurus poderiam apresentar exigências de mantença inferiores as exigências apresentadas pelas raças puras taurinas em condições similares. Outro ponto importante a salientar é a condição sexual dos animais e as referentes ao tamanho adulto das raças avaliadas como elementos que condicionam as maiores ou menores exigências de mantença por unidade de peso vivo.

Assim, hipotetizou-se que haveria maior percentual de trato gastrintestinal nos animais em pastejo devido à menor concentração calórica da dieta que aumenta as exigências de mantença e consequentemente aumenta $\mathrm{o}$ trato gastrintestinal. A outra hipótese foi que independentemente do tratamento haveria maior percentual de trato gastrintestinal dos Bos taurus em relação aos Bos indicus devido à menor ingestão por bocado e maior frequência de consumo dos Bos indicus.

Neste trabalho objetivou-se avaliar as características das partes do corpo vazio não-integrantes da carcaça de novilhos de três grupos genéticos, terminados em confinamento ou pastejo rotacionado com suplementação. 
Rev. Bras. Saúde Prod. Anim., Salvador, v.14, n.1, p.209-223 jan./mar., 2013 http://www.rbspa.ufba.br ISSN 15199940

\section{MATERIAL E MÉTODOS}

O experimento foi realizado no Centro Tecnológico Agropecuário do Paraguai (CETAPAR), localizado no município de Yguaçu, distante $287 \mathrm{~km}$ de Assunção. Foram utilizados 36 bovinos machos castrados (novilhos) das raças: Hereford adaptado, Brahman e Brangus, com idade média de 22 meses e pesos iniciais $395 \pm 18 \mathrm{~kg}$.

Seis animais de cada raça foram terminados em sistema de pastejo rotacionado de capim mombaça (7\% PB e $56 \%$ NDT), com quatro dias de utilização e intervalos fixos entre pastejos de 32 dias para cada piquete. $\mathrm{O}$ suplemento fornecido foi composto de milho (30\%), subproduto da limpeza de silo de soja $(69,5 \%)$ e sal mineral $(0,5 \%)$, oferecido na quantidade de $1 \%$ peso vivo. $\mathrm{O}$ suplemento apresentou uma composição de $27 \%$ PB e $70 \%$ NDT.

Seis animais de cada raça foram mantidos confinados, mantidos em baias individuais cobertas e piso pavimentado de concreto armado, com área de $6 \mathrm{~m}^{2}$ por animal, alimentados à vontade, duas vezes ao dia. A dieta foi calculada, objetivando-se um ganho de peso médio diário de $1,1 \mathrm{~kg} /$ animal e estimando-se um consumo de $2,5 \mathrm{~kg}$ de matéria seca (MS)/100kg de peso vivo. Foi utilizada uma relação volumoso:concentrado de 60:40 (base na matéria seca), com uma dieta final contendo $12 \%$ de PB e $64 \%$ NDT. Os ingredientes e suas composições percentuais foram: silagem de milho (50\%), grão de milho (10\%), subproduto da limpeza de silo soja (30\%), feno de capim mombaça $(9,5 \%)$ e sal mineral $(0,5)$. Na tabela 1 encontram-se a composição detalhada das dietas.

Tabela 1: Composição nutricional e proporção dos ingredientes das dietas experimentais

\begin{tabular}{|c|c|c|c|c|c|c|}
\hline \multirow[b]{2}{*}{ Item } & \multicolumn{3}{|c|}{ Pastejo com suplementação } & \multicolumn{3}{|c|}{ Confinamento } \\
\hline & $\begin{array}{c}\text { Capim } \\
\text { mombaça }\end{array}$ & Concentrado & Dieta & Volumoso & Concentrado & Dieta \\
\hline Composição dieta (\%) & 70 & 30 & 100 & 59 & 41 & 100 \\
\hline $\operatorname{MS}(\%)$ & 27 & 89 & $52 \%$ & 25 & 89,1 & 51,28 \\
\hline $\mathrm{PB}(\%)$ & 7 & 27 & $13 \%$ & 8 & 20 & 12,92 \\
\hline $\mathrm{FDN}(\%)$ & 70 & 33 & $52 \%$ & 60 & 14,9 & 42,71 \\
\hline \multirow[t]{2}{*}{ NDT $(\%)$} & 56 & 70 & 64,4 & 62 & 75 & 67,33 \\
\hline & & MS ( \%) & $\mathrm{MO}(\%)$ & PB ( \%) & FDN ( \%) & $\operatorname{FDA}(\%)$ \\
\hline \multicolumn{7}{|c|}{ Pastejo com suplementação } \\
\hline Capim mombaça & - & 27,00 & 91,18 & 7,00 & 70,00 & 38,37 \\
\hline Milho móido & - & 87,10 & 98,40 & 8,20 & 12,00 & 4,30 \\
\hline $\begin{array}{l}\text { Subproduto limpeza } \\
\text { silo soja }\end{array}$ & - & 88,00 & 92,34 & 24,00 & 43,00 & 5,50 \\
\hline \multicolumn{7}{|l|}{ Confinamento } \\
\hline Silagem de milho & - & 27,00 & 93,66 & 7,20 & 48,30 & 25,84 \\
\hline Grão de milho & - & 87,00 & 85,84 & 8,00 & 11,00 & 3,40 \\
\hline $\begin{array}{l}\text { Subproduto limpeza } \\
\text { silo soja }\end{array}$ & - & 88,00 & 92,34 & 24,00 & 43,00 & 5,50 \\
\hline Feno capim mombaça & - & 85,00 & 93,66 & 8,00 & 70,00 & 29,45 \\
\hline
\end{tabular}

$\mathrm{MS}=$ matéria seca; $\mathrm{PB}=$ proteína bruta; $\mathrm{FDN}$ = fibra em detergente neutro; $\mathrm{NDT}=$ nutrientes digestíveis totais; $\mathrm{MO}=$ matéria orgânica; FDA = fibra em detergente ácido. 
As pesagens foram realizadas a cada 28 dias onde se avaliou a espessura de gordura subcutânea do dorso por meio de ultrassonografia, feita com um aparelho ALOKA com unidade principal SSD-500 para uso veterinário e um transdutor modelo UST-5044-3,5 (3,5Mhz-172mm), na região entre a $12^{\mathrm{a}}$ e $13^{\mathrm{a}}$ costela e, quando os animais apresentaram espessura de gordura superior a $4 \mathrm{~mm}$, foram encaminhados para o abate. Todas as mensurações foram realizadas pela mesma pessoa. Todos os animais foram pesados na origem, no dia anterior ao abate e foram transportados sem jejum até o frigorífico, distante $300 \mathrm{~km}$ da fazenda experimental. O desembarque ocorreu as 22 horas do mesmo dia e, a partir desse horário, os animais foram mantidos em currais de espera com jejum de sólidos por 12 horas antes da ultima pesagem, considerado como peso de abate (PA).

Os animais foram abatidos de acordo com os padrões do Serviço Nacional de Qualidade e Sanidade Animal do Paraguai (SENACSA), adotados pelo Frigorifico Agrofrio. O abate foi feito com dardo cativo com pistola pneumática para insensibilização, e durante o abate, todas as partes do corpo do animal foram separadas, pesadas e identificadas individualmente, e consistiram de: conjunto de componentes externos cabeça, pata, vassoura da cauda e pele; conjunto de órgãos vitais (coração, rins, pulmão, fígado e baço); conjunto de gorduras internas (gordura do coração, gordura do fígado, gordura renal, gordura de toalete e gordura mensentérica); conjunto do trato digestivo vazio (rúmenretículo, omaso, abomaso, intestinos (intestino grosso + intestino delgado) vazios e sangue.

Antes de serem encaminhadas à câmara de resfriamento (entre 0 e $5^{\circ} \mathrm{C}$ por 24 horas), as duas meias-carcaças foram identificadas e pesadas, obtendo-se o peso de carcaça quente (PCQ). O peso de corpo vazio (PCV) foi obtido pelo somatório do peso de carcaça quente, sangue e de todos os componentes agrupados, conforme citado anteriormente.

O delineamento experimental foi inteiramente casualizado, com arranjo fatorial $3 \times 2$ (três grupos genéticos e dois sistemas de terminação). Cada tratamento foi composto de seis repetições onde cada animal constituiu uma unidade experimental.

Os dados foram analisados utilizando o procedimento GLM do pacote estatístico SAS® versão 9,1 para Windows ${ }^{\circledR}$, (SAS Institute, 2003). A comparação de médias foi realizada pelo teste de Tukey ajustado adotando-se um nível de significância de $5 \%$.

\section{RESULTADOS E DISCUSSÃO}

Como não houve efeito da interação entre o sistema de terminação e o grupo genético para o peso de abate (PA), peso de corpo vazio (PCV) e rendimento de carcaça (RC), os efeitos foram estudados separadamente (Tabela 2). Os pesos iniciais e finais dos animais terminados em confinamento foram inferiores $(\mathrm{P}<0,0035)$ aos apresentados pelos animais terminados em pastejo $(403,54 \mathrm{~kg}$ vs $438,56 \mathrm{~kg})$. Os novilhos Hereford adaptado apresentaram menores pesos de abate do que Brahaman e Brangus $(\mathrm{P}<0,05)$. Estas diferenças podem ser em decorrência das diferenças de frame existentes entre estes dois grupos raciais (Brahman e Brangus) e o Hereford. A mesma tendência foi observada ao avaliar o peso de corpo vazio (PCV) dos animais nas três raças e sistemas de terminação empregados (Tabela 2). 
Rev. Bras. Saúde Prod. Anim., Salvador, v.14, n.1, p.209-223 jan./mar., 2013 http://www.rbspa.ufba.br ISSN 15199940

Tabela 2. Médias e erro padrão (EP) do peso de abate, do peso de corpo vazio e do rendimento de corpo vazio de acordo com o sistema de alimentação e o grupo genético avaliado

\begin{tabular}{|c|c|c|c|c|}
\hline \multirow{2}{*}{ Grupo genético } & \multicolumn{2}{|c|}{ Sistema de terminação } & \multirow{2}{*}{ Média } & \multirow{2}{*}{$\mathrm{EP}$} \\
\hline & Pastejo & Confinamento & & \\
\hline \multicolumn{5}{|c|}{ Peso de abate $(\mathrm{kg})$} \\
\hline Hereford & 393,05 & 381,65 & $385,45^{\mathrm{b}}$ & 17,6 \\
\hline Brangus & 446,95 & 414,04 & $430,49^{\mathrm{a}}$ & 11,6 \\
\hline Brahman & 468,11 & 429,53 & $448,82^{\mathrm{a}}$ & 15,6 \\
\hline Média & $438,56^{\mathrm{A}}$ & $403,54^{\mathrm{B}}$ & - & - \\
\hline EP & 22,47 & 21,47 & - & - \\
\hline \multicolumn{5}{|c|}{ Peso de corpo vazio $(\mathrm{kg})$} \\
\hline Hereford & 365,74 & 352,57 & $357,03^{b}$ & 16,8 \\
\hline Brangus & 420,87 & 385,65 & $403,26^{\mathrm{a}}$ & 15,8 \\
\hline Brahman & 435,13 & 402,45 & $418,79^{\mathrm{a}}$ & 14,8 \\
\hline Média & $409,68^{\mathrm{A}}$ & $375,24^{\mathrm{B}}$ & - & - \\
\hline EP & 17,59 & 18,59 & - & - \\
\hline \multicolumn{5}{|c|}{ Rendimento do corpo vazio (\%) } \\
\hline Hereford & 93,05 & 92,50 & 92,77 & 3,9 \\
\hline Brangus & 94,06 & 93,14 & 93,60 & 4,7 \\
\hline Brahman & 92,95 & 93,60 & 93,28 & 3,2 \\
\hline Média & 93,35 & 93,00 & - & - \\
\hline EP & 5,15 & 4,15 & - & - \\
\hline $\begin{array}{l}\text { Suplemento: milho }(30 \\
\text { na quantidade de } 1 \% \mathrm{p} \\
{ }_{\mathrm{a}, \mathrm{b}, \mathrm{c}} \text { Médias seguidas } \mathrm{p} \\
(\mathrm{p}<0,05) \text { pelo teste de } \\
\mathrm{A}, \mathrm{B} \text { Médias seguidas } \mathrm{p}\end{array}$ & $\begin{array}{l}\text { uto da liml } \\
\text { lúsculas di } \\
\text { iúsculas d }\end{array}$ & $\begin{array}{l}\text { e soja }(69,5 \%) \\
\text { oluna, para a } n\end{array}$ & $\begin{array}{l}\text { neral }(0,5 \\
\text { caracterís }\end{array}$ & $\begin{array}{l}\text { ferec } \\
\text { difer }\end{array}$ \\
\hline
\end{tabular}

Foi obtido um rendimento médio de corpo vazio de $93 \%$ independentemente do sistema de terminação e do grupo genético avaliado $(\mathrm{P}<0,20)$. Este valor está acima dos 89,1 estabelecidos pelo CNCPS (2003) e próximos aos valores de 91 e $93,3 \%$ encontrados por Kuss et al. (2008) em novilhos $1 / 2$ Purunã (1/2 Angus $+1 / 4$ Charolês $+1 / 4$ Caracu $+1 / 4$ Canchim) $+1 / 2$ Canchim terminados em confinamento e Macitelli et al. (2005) em bovinos mestiços Holandês-Zebu terminados com diferentes fontes protéicas e volunosos, respectivamente. Apesar das variações entre o grupo genético e o sistema de terminação avaliado para PA e PCV, o rendimento do corpo vazio foi similar, embora que o trato gastrintestinal tenha sido inferior para o Brahman, essa diferença não afetou o rendimento de corpo vazio, o que pode ser explicado pelo maior peso total de componentes externos, influenciado principalmente pelos maiores pesos dos pés e da pele nesta raça.

Os animais terminados em pastejo com suplementação apresentaram maior peso total de componentes externos (Tabela $3)$. Houve superioridade do Brahman com relação ao Brangus e Hereford $(\mathrm{P}<0,05)$ tanto em PA como em \% PCV. 
Rev. Bras. Saúde Prod. Anim., Salvador, v.14, n.1, p.209-223 jan./mar., 2013 http://www.rbspa.ufba.br ISSN 15199940

Tabela 3. Médias e erro padrão (EP) dos totais de componentes externos, de órgãos vitais, de gordura interna, do trato digestivo vazio e do sangue, expressos em peso absoluto (PA) e em percentual de peso de corpo vazio (\%PCV), de acordo com o sistema de alimentação e o grupo genético avaliado

\begin{tabular}{|c|c|c|c|c|c|c|c|c|}
\hline \multirow{2}{*}{$\begin{array}{l}\text { Grupo } \\
\text { genético }\end{array}$} & \multicolumn{2}{|c|}{ Sistema de terminação } & \multirow{2}{*}{ Média } & \multirow{2}{*}{$\mathrm{EP}$} & \multicolumn{2}{|c|}{ Sistema de terminação } & \multirow{2}{*}{ Média } & \multirow{2}{*}{$\mathrm{EP}$} \\
\hline & Pastejo & Confinamento & & & Pastejo & Confinamento & & \\
\hline & \multicolumn{2}{|c|}{$\begin{array}{l}\text { Total componentes } \\
\text { externos }(\mathrm{kg})\end{array}$} & \multicolumn{6}{|c|}{$\begin{array}{l}\text { Total componentes } \\
\text { externos }(\% \mathrm{PCV})\end{array}$} \\
\hline Hereford & 65,25 & 63,23 & $64,24^{\mathrm{b}}$ & 9,3 & 17,78 & 16,31 & $16,54^{\mathrm{b}}$ & 7,8 \\
\hline Brangus & 68,02 & 60,21 & $64,11^{\mathrm{b}}$ & 8,7 & 17,22 & 15,46 & $16,34^{\mathrm{b}}$ & 7,3 \\
\hline Brahman & 72,50 & 67,18 & $69,84^{\mathrm{a}}$ & 9,5 & 18,50 & 17,12 & $17,80^{\mathrm{a}}$ & 6,5 \\
\hline Média & $68,62^{\mathrm{A}}$ & $63,54^{\mathrm{B}}$ & - & - & $17,83^{\mathrm{A}}$ & $16,30^{\mathrm{B}}$ & - & - \\
\hline \multirow[t]{2}{*}{ EP } & 11,5 & 10,5 & - & - & 6,33 & 6,33 & - & - \\
\hline & \multicolumn{2}{|c|}{ Total órgãos vitais (kg) } & \multicolumn{6}{|c|}{$\begin{array}{c}\text { Total órgãos vitais } \\
(\% \mathrm{PCV})\end{array}$} \\
\hline Hereford & $12,24^{\mathrm{ab}}$ & $12,01^{\mathrm{a}}$ & 12,13 & 112,5 & 3,13 & 3,11 & $3,12^{\mathrm{a}}$ & 7,3 \\
\hline Brangus & $13,14^{\mathrm{a}}$ & $11,70^{\mathrm{ab}}$ & 12,42 & 11,1 & 3,40 & 2,90 & $3,18^{\mathrm{a}}$ & 7,3 \\
\hline Brahman & $10,50^{\mathrm{b}}$ & $10,50^{\mathrm{b}}$ & 10,49 & 1112,3 & 1,72 & 2,65 & $2,19^{\mathrm{b}}$ & 5,6 \\
\hline Média & 12,96 & 11,40 & - & - & 2,80 & 2,89 & - & - \\
\hline \multirow[t]{2}{*}{$\mathrm{EP}$} & 9,0 & 8,9 & - & - & 6,01 & 5,25 & - & - \\
\hline & \multicolumn{2}{|c|}{ Total gordura interna (kg) } & \multicolumn{6}{|c|}{$\begin{array}{l}\text { Total gordura interna } \\
(\% \mathrm{PCV})\end{array}$} \\
\hline Hereford & $20,41^{\mathrm{a}}$ & 20,06 & 20,24 & 11,1 & $5,22^{a}$ & $5,20^{\mathrm{a}}$ & 5,21 & 7,3 \\
\hline Brangus & $12,99^{\mathrm{bB}}$ & $22,19^{\mathrm{A}}$ & 17,57 & 11,5 & $3,36^{\mathrm{bB}}$ & $5,68^{\mathrm{aA}}$ & 4,52 & 6,9 \\
\hline Brahman & $27,52^{\mathrm{ab}}$ & 18,25 & 17,88 & 12,2 & $4,49^{\mathrm{b}}$ & $4,63^{\mathrm{b}}$ & 4,56 & 6,9 \\
\hline Média & 19,96 & 20,16 & - & - & 4,33 & 5,17 & - & - \\
\hline \multirow[t]{2}{*}{$\mathrm{EP}$} & 11,5 & 10,4 & - & - & 2,33 & 2,00 & - & - \\
\hline & \multicolumn{2}{|c|}{$\begin{array}{l}\text { Total trato digestivo vazio } \\
(\mathrm{kg})\end{array}$} & \multicolumn{6}{|c|}{$\begin{array}{c}\text { Total trato digestivo } \\
\text { vazio }(\% \mathrm{PCV})\end{array}$} \\
\hline Hereford & $18,89^{\mathrm{a}}$ & $18,23^{\mathrm{a}}$ & 18,56 & 9,4 & $5,00^{\mathrm{a}}$ & $4,74^{\mathrm{ab}}$ & 4,87 & 2,7 \\
\hline Brangus & $15,31^{\mathrm{b}}$ & $18,46^{\mathrm{a}}$ & 16,84 & 9,7 & $3,29^{\mathrm{bB}}$ & $5,27^{\mathrm{aA}}$ & 4,48 & 7,7 \\
\hline Brahman & $15,80^{\mathrm{b}}$ & $14,82^{\mathrm{b}}$ & 15,31 & 8,6 & $3,76^{\mathrm{b}}$ & $3,76^{\mathrm{b}}$ & 3,77 & 2.0 \\
\hline Média & 16,67 & 17,17 & - & - & 4,15 & 4,59 & - & - \\
\hline \multirow[t]{2}{*}{ EP } & 8,0 & 8,2 & - & - & 6,5 & 6,0 & - & - \\
\hline & \multicolumn{2}{|c|}{ Sangue (kg) } & \multicolumn{6}{|c|}{ Sangue (\%PCV) } \\
\hline Hereford & $12,77^{\mathrm{ab}}$ & 13,12 & 12,95 & 1,2 & 3,30 & 3,43 & $3,36^{\mathrm{a}}$ & 1,0 \\
\hline Brangus & $13,56^{\mathrm{a}}$ & 11,02 & 12,29 & 1,5 & 3,43 & 2,81 & $3,12^{\mathrm{a}}$ & 1,1 \\
\hline Brahman & $10,37^{\mathrm{b}}$ & 10,81 & 10,59 & 1,2 & 2,76 & 2,76 & $2,76^{\mathrm{b}}$ & 1,0 \\
\hline Média & 12,24 & 11,65 & - & - & 3,16 & 3,00 & - & - \\
\hline $\mathrm{EP}$ & 8,04 & 8,07 & - & - & 1,5 & 1,2 & - & - \\
\hline
\end{tabular}

Suplemento: milho (30\%), subproduto da limpeza de silo de soja $(69,5 \%)$ e sal mineral $(0,5 \%)$ oferecido na quantidade de $1 \%$ peso vivo.

${ }_{\mathbf{a}, \mathbf{b}, \mathbf{c}}$ Médias seguidas por letras minúsculas diferentes na coluna, para a mesma característica, diferem $(\mathrm{p}<0,05)$ pelo teste de Tukey.

${ }_{\mathrm{A}, \mathbf{B}}$ Médias seguidas por letras maiúsculas diferentes na linha, para a mesma característica diferem $(\mathrm{p}<0,05)$ pelo teste de $\mathrm{t}$. 
Os Bos indicus, apresentam maior superfície de pele para a mesma massa corporal, produto das adaptações para facilitar a eliminação de calor corporal em situações de estresse calórico (Di MARCO et al., 2007). Neste sentido, esperava-se uma resposta intermédia dos cruzados (Brangus), que não ocorreu em relação ao Hereford. Cattletam et al. (2011) também observaram que peso total de componentes externos foi superior para novilhos com predominância nelore no genético influenciado principalmente pela superioridade do peso da pele.

Foi observada interação significativa entre o grupo genético e o sistema de terminação para o total de órgãos vitais. No entanto, a mesma não foi observada em \%PCV, em que os animais Hereford e Bangus (3,12 e 3,18\%) apresentaram maiores pesos dos órgãos vitais que o Brahman $(2,19 \%)(\mathrm{P}<0,03)$. O peso dos órgãos vitais foi correlacionado positivamente com os pesos do fígado $(\mathrm{r}=0,89)$, pulmão $(\mathrm{r}=0,80)$, baço $(0,63)$, rins $(r=0,60)$ e coração $(r=0,51)$.

Houve interação entre o sistema de terminação e as raças para o total de gordura interna expresso em PA e \%PCV. Em pastejo com suplementação, tanto animais Hereford como Brahman, tiveram comportamento similar e superior aos animais Brangus. Quando o total de gordura interna foi apresentado como \%PCV o Hereford foi superior às demais raças. No confinamento os dados de total de gordura interna expressos em PA são similares em todas as raças, produto da padronização do sistema de terminação, porém quando expressos como \% PCV o Hereford e o Brangus (5,20 e 5,68\%) foram superiores ao Brahman $(4,63 \%)$ $(\mathrm{P}<0,05)$. O Brangus em sistema de confinamento mostrou um percentual maior de gordura interna que no sistema de pastejo com suplementação (40\% superior).

Foi observada interação significativa $(\mathrm{P}<0,05)$ entre raça e sistema de terminação em relação ao total do trato gastrintestinal tanto em PA como em $\% \mathrm{PCV}$, mostrando que o Hereford terminado em pastejo obteve os maiores pesos em PA e \%PCV de trato gastrintestinal $(\mathrm{P}<0,032) . \quad \mathrm{Em}$ confinamento, tanto em PA como em \%PCV o Brangus e o Hereford apresentaram trato gastrintestinal similares, mas superiores ao Brahman $(\mathrm{P}<0,03)$. Estes resultados podem estar associados aos maiores consumos de MS observados nas raças européias em relação ao Brahman (RENNÓ et al., 2005).

O peso total do trato digestivo esteve correlacionado significativamente com o peso dos intestinos $(\mathrm{r}=0,76)$, seguido pelo peso vazio do omaso $(r=0,65)$. Valadares Filho et al. (2009) destacaram que o Nelore e cruzas têm menores exigências de energia de mantença, pelo fato de terem um peso inferior dos órgãos internos que os Bos taurus.

Para o componente sangue (Tabela 3) houve interação significativa entre as raças e sistemas de terminação, mas esta desapareceu quando estes dados foram corrigidos para \%PCV. Neste caso, houve diferença favorável para $\mathrm{o}$ Hereford e o Brangus com maior peso relativo do sangue que o Brahman $(\mathrm{P}<0,033)$. Este resultado poderia ser parcialmente explicado pela relação do sangue com o peso dos órgãos vitais e com o trato digestivo vazio, pois como eles são os principais responsáveis pelo aumento do metabolismo e pelos gastos de mantença é necessário maior volume de sangue para manter a taxa metabólica destes animais (RIBEIRO et al., 2000; PACHECO et al., 2005). Pacheco et al. (2005) encontraram que os novilhos com maior predominância de sangue 
Charolês apresentaram maior peso de sangue do que os novilhos com predominância de sangue Nelore. Portanto, considerando os resultados obtidos neste experimento, de maneira geral, os valores de cada componente avaliado, estão de acordo com a literatura (PACHECO et al., 2005; RESTLE et al., 2005; KUSS et al., 2008, MENEZES et al., 2011), com exceção da percentagem de trato digestivo vazio que foi inferior a 9,48; 7,24 e 9,85 obtidas por Macitelli et al. (2005), Pacheco et al. (2005) e Kuss et al. (2008), respectivamente, em condições experimentais semelhantes. No entanto, é possível que estas diferenças estejam associadas ao maior período de jejum aplicado nestes trabalhos.

Não houve diferença significativa para o peso do coração entre os sistemas de terminação, entretanto, o peso do coração (Tabela 4) foi superior para o Brangus em PA e quando foi ajustado a $\%$ PCV o Brangus foi similar ao Hereford, sendo ambos superiores ao Brahman $(\mathrm{P}<0,05)$. Avaliando estes dados em conjunto com a Tabela 3 , observa-se um conteúdo de sangue como \%PCV superior para o Hereford e Brangus, podendo-se inferir em consequiência da necessidade de um coração maior em relação ao Brahman.

Segundo Cumby (2000), os órgãos vitais apresentam diferentes taxas metabólicas em comparação às das demais partes do corpo. O tamanho e a taxa metabólica dos órgãos sofrem modificações quando os animais são submetidos a dietas diferindo em qualidade e/ou quantidade, e estão diretamente relacionadas às exigências de energia para mantença dos animais.

$\mathrm{O}$ peso dos rins (Tabela 4) não diferiu entre as raças avaliadas $(\mathrm{P}<0,05)$, mas foi superior para animais terminados em sistema de pastejo com o mesmo diferencial nas duas formas de apresentação dos dados: PA e \%PCV.
O peso do pulmão (Tabela 4) apresentou superioridade no Hereford e Brangus $(0,77 \%$ e $0,78 \%)$ em relação ao Brahman $(0,68 \%)$ em PA e em \%PCV $(\mathrm{P}<0,05)$. Os animais terminados em pastejo tiveram maior peso do que os terminados em confinamento.

Quanto ao fígado, maiores pesos foram verificados para os animais da raça Brangus em PA e em \%PCV ( $\mathrm{P}<0,04)$. Segundo McBride \& Kelly (1990) e Hersom et al. (2004), o sistema porta e o fígado são responsáveis por $50 \%$ do consumo de $\mathrm{O}_{2}$, porém representam entre 8 a $14 \%$ do peso corporal do animal. O tamanho e a taxa metabólica dos órgãos sofrem modificações quando os animais são submetidos a dietas, diferindo em qualidade e quantidade, e estão diretamente relacionadas às exigências de energia para mantença dos animais. Quando os animais estão em estresse nutricional, os primeiros tecidos a serem mobilizados são os de maior taxa metabólica, como o fígado e o trato digestivo (CUMBY et al., 2000; PACHECO et al., 2005; DI MARCO et al., 2007), resultando em menores exigências de mantença. Este quadro se mantém durante $\mathrm{o}$ período de realimentação, até o restabelecimento completo destes componentes, ocorrendo, então, aumento nas exigências de mantença dos animais. Este período e variável e pode ser de até 90 dias. Neste sentido, ao avaliar os ganhos médios diários no período pré-terminação, onde tanto os animais terminados em pastejo como os de confinamento tiveram ganhos médios diários relativamente baixos de 0,53 e $0,48 \mathrm{~kg} / \mathrm{cab} / \mathrm{dia}$, permite supor que o ganho compensatório poderia ter possibilitado manter as exigências de mantença diminuídas, associadas a tamanhos do trato gastrintestinal e órgãos vitais inferiores, pelo menos no primeiro mês, independente do sistema de terminação. 
Rev. Bras. Saúde Prod. Anim., Salvador, v.14, n.1, p.209-223 jan./mar., 2013 http://www.rbspa.ufba.br ISSN 15199940

Tabela 4. Médias e erro padrão (EP) dos pesos do coração, dos rins, do pulmão, do fígado e do baço, expressos em peso absoluto (PA) e em percentual de peso de corpo vazio (\%PCV), de acordo com o sistema de alimentação e o grupo genético avaliado

\begin{tabular}{|c|c|c|c|c|c|c|c|c|}
\hline \multirow{2}{*}{$\begin{array}{l}\text { Grupo } \\
\text { genético }\end{array}$} & \multicolumn{2}{|c|}{ Sistema de terminação } & \multirow{2}{*}{ Média } & \multirow{2}{*}{$\mathrm{EP}$} & \multicolumn{2}{|c|}{ Sistema de terminação } & \multirow{2}{*}{ Média } & \multirow{2}{*}{$\mathrm{EP}$} \\
\hline & Pastejo & Confinamento & & & Pastejo & Confinamento & & \\
\hline & \multicolumn{2}{|c|}{ Coração (kg) } & \multicolumn{6}{|c|}{ Coração (\%PCV) } \\
\hline Hereford & 1,48 & 1,49 & $1,48^{\mathrm{ab}}$ & 0,09 & 0,39 & 0,39 & $0,38^{\mathrm{a}}$ & 0,02 \\
\hline Brangus & 1,65 & 1,49 & $1,57^{\mathrm{a}}$ & 0,08 & 0,41 & 0,39 & $0,40^{\mathrm{a}}$ & 0,02 \\
\hline Brahman & 1,23 & 1,28 & $1,25^{\mathrm{b}}$ & 0,09 & 0,33 & 0,33 & $0,33^{\mathrm{b}}$ & 0,04 \\
\hline Média & 1,45 & 1,42 & - & - & 0,38 & 0,37 & - & - \\
\hline \multirow[t]{2}{*}{$\mathrm{EP}$} & 0,06 & 0,07 & - & - & 0,03 & 0,03 & - & - \\
\hline & \multicolumn{2}{|c|}{ Rins (kg) } & \multicolumn{6}{|c|}{ Rins (\%PCV) } \\
\hline Hereford & 0,95 & 0,81 & 0,88 & 0,10 & 0,77 & 0,77 & 0,30 & 0,10 \\
\hline Brangus & 0,94 & 0,85 & 0,90 & 0,21 & 0,83 & 0,73 & 0,32 & 0,11 \\
\hline Brahman & 0,88 & 0,81 & 0,84 & 0,10 & 0,72 & 0,65 & 0,28 & 0,09 \\
\hline Média & $0,92^{\mathrm{A}}$ & $0,82^{\mathrm{B}}$ & - & - & $0,77^{\mathrm{A}}$ & $0,71^{\mathrm{B}}$ & - & - \\
\hline \multirow[t]{2}{*}{$\mathrm{EP}$} & 0,09 & 0,10 & - & - & 0,07 & 0,06 & - & - \\
\hline & \multicolumn{2}{|c|}{ Pulmão (kg) } & \multicolumn{6}{|c|}{ Pulmão (\%PCV) } \\
\hline Hereford & 3,00 & 2,97 & $2,98^{\mathrm{a}}$ & 0,90 & 0,77 & 0,77 & $0,77^{\mathrm{a}}$ & 0,09 \\
\hline Brangus & 3,27 & 2,80 & $3,04^{\mathrm{a}}$ & 0,70 & 0,83 & 0,73 & $0,78^{\mathrm{a}}$ & 0,09 \\
\hline Brahman & 2,75 & 2,49 & $2,61^{\mathrm{b}}$ & 0,70 & 0,72 & 0,65 & $0,68^{\mathrm{b}}$ & 0,10 \\
\hline Média & $3,00^{\mathrm{A}}$ & $2,75^{\mathrm{B}}$ & - & - & $0,77^{\mathrm{A}}$ & $0,71^{\mathrm{B}}$ & - & - \\
\hline \multirow[t]{2}{*}{$\mathrm{EP}$} & 1,1 & 1,0 & - & - & 0,10 & 0,25 & - & - \\
\hline & \multicolumn{2}{|c|}{ Fígado $(\mathrm{kg})$} & \multicolumn{6}{|c|}{ Fígado (\%PCV) } \\
\hline Hereford & 5,35 & 5,23 & $5,29^{a}$ & 1,20 & 1,39 & 1,33 & $1,37^{\mathrm{ab}}$ & 0,90 \\
\hline Brangus & 5,91 & 5,24 & $5,57^{\mathrm{a}}$ & 1,50 & 1,49 & 1,36 & $1,43^{\mathrm{a}}$ & 0,95 \\
\hline Brahman & 4,68 & 4,87 & $4,78^{\mathrm{b}}$ & 0,90 & 1,22 & 1,25 & $1,24^{\mathrm{b}}$ & 0,75 \\
\hline Média & $5,31^{\mathrm{A}}$ & $5,11^{\mathrm{B}}$ & - & - & 1,36 & 1,32 & - & - \\
\hline \multirow[t]{2}{*}{ EP } & 1,80 & 1,70 & - & - & $+-0,95$ & $+-0,58$ & - & - \\
\hline & \multicolumn{2}{|c|}{ Baço (kg) } & \multicolumn{6}{|c|}{ Baço (\%PCV) } \\
\hline Hereford & 1,44 & 1,51 & $1,48^{\mathrm{a}}$ & 0,10 & 0,37 & 0,40 & $0,38^{\mathrm{a}}$ & 0,08 \\
\hline Brangus & 1,36 & 1,33 & $1,34^{\mathrm{a}}$ & 0,09 & 0,34 & 0,34 & $0,34^{\mathrm{a}}$ & 0,05 \\
\hline Brahman & 0,45 & 1,04 & $1,00^{\mathrm{b}}$ & 0,12 & 0,25 & 0,27 & $0,26^{\mathrm{b}}$ & 0,08 \\
\hline Média & 1,25 & 1,30 & - & - & 0,32 & 0,34 & - & - \\
\hline EP & 1,1 & 0,9 & - & - & 0,08 & 0,06 & - & - \\
\hline
\end{tabular}

Suplemento: milho (30\%), subproduto da limpeza de silo de soja $(69,5 \%)$ e sal mineral $(0,5 \%)$ oferecido na quantidade de $1 \%$ peso vivo.

a,b,c Médias seguidas por letras minúsculas diferentes na coluna, para a mesma característica, diferem $(\mathrm{p}<0,05)$ pelo teste de Tukey.

${ }_{\mathrm{A}, \mathrm{B}}$ Médias seguidas por letras maiúsculas diferentes na linha, para a mesma característica diferem $(\mathrm{p}<0,05)$ pelo teste de $\mathrm{t}$

EP erro padrão da media.

Os animais Hereford e Brangus apresentaram similaridade nos componentes do conjunto dos órgãos vitais (pulmão, fígado, rins, baço $\mathrm{e}$ coração) - $(\mathrm{P}>0,23)$, corroborando com os dados apresentados por Santos et al. (2003b) que observaram similaridade entre animais Chianina $(\mathrm{CH})$ e $3 / 4 \mathrm{CH}$ 1/4 Nelore (NE), em valores ajustados para \%PCV para esta característica. 
De maneira geral os valores encontrados neste trabalho para peso de fígado corrigido para \%PCV foram semelhantes aos encontrados por Véras et al. (2001) e Pacheco et al. (2005) de $1,32 \%$ para bovinos Nelore não-castrados e para novilhos jovens e superjovens $5 / 8$ Charolês (CH) 3/8 Nelore (NE) e 5/8NE $3 / 8 \mathrm{CH}$, respectivamente e superiores aos encontrados por Kuss et al. (2008) e Restle et al. (2005) de 1,28\% para novilhos $1 / 2$ Purunã ( $1 / 2$ Angus $+1 / 4$ Charolês $+1 / 4$ Caracu $+1 / 4$ Canchim) $+1 / 2$ Canchim terminados em confinamento e para novilhos 5/8 Nelore 3/8 Charolês terminados em confinamento e abatidos com 425; 467 e $510 \mathrm{~kg}$, respectivamente. $\mathrm{Na}$ gordura de toalete, em que são retirados os excessos de gordura, houve interação significativa entre raças e sistema de terminação, mostrando superioridade do Hereford para animais terminados em pastejo (Tabela 5). Em geral, pelo sistema de abate relacionado ao grau de acabamento (> $4 \mathrm{~mm}$ ), não foram observadas diferenças entre as raças e entre o sistema de terminação. Não houve diferença entre as raças terminadas em confinamento em razão da maior homogeneidade no grau de acabamento de suas carcaças. $\mathrm{O}$ fato de não apresentar diferenças entre os animais confinados poderia estar relacionado aos ganhos médios diários similares apresentados pelas três raças (1,2kg/cab/dia). Avaliando o efeito do sistema de terminação sobre as raças observa-se superioridade dos Brangus e Brahman terminados em confinamento comparados aos terminados em pastejo $(\mathrm{P}<0,05)$, possivelmente como resultado dos ganhos médios diários superiores. Os valores para ganhos de peso do confinamento considerados altos e os ganhos de peso do pastejo considerados médios observados no presente trabalho são similares aos obsevados por Hersom et al. (2004) de $3,97 \%$ vs $3,0 \%$, respectivamente; em animais Angus e Angus-Hereford com altos e baixos ganhos médios diários; são inferiores aos apresentados por Kuss et al. (2008) de 2,78 em \% PCV em novilhos $1 / 2$ Purunã $(1 / 2$ Angus $+1 / 4$ Charolês $+1 / 4$ Caracu $+1 / 4$ Canchim) $+1 / 2$ Canchim terminados em confinamento; e muito inferiores aos apresentados por Pacheco et al. (2005) de 0,72 \% PCV em novilhos jovens e superjovens 5/8 Charolês (CH) 3/8 Nelore (NE) e 5/8NE $3 / 8 \mathrm{CH}$ terminados em confinamento. Estas diferenças podem ser causadas pelas práticas relativas ao manejo dos frigoríficos, supondo uma maior ou menor extração de gordura de toalete de acordo as exigências da indústria.

$\mathrm{O}$ peso da gordura mesentérica apresentou interação significativa entre as raças e o sistema de terminação. $\mathrm{O}$ peso da gordura mesentérica foi superior nas raças Brahman e Hereford em relação ao Brangus no sistema de pastejo, contudo no sistema de confinamento as raças Brangus e Hereford foram as que apresentaram maior o peso (Tabela 6). O Brangus em confinamento apresentou superioridade em comparação ao Brangus mantido em pastejo $(\mathrm{P}<0,05)$. Em todos os casos a quantidade de gordura mesentérica demonstrou ter correlação positiva $(\mathrm{r}=0,56, \quad \mathrm{P}<0,01)$ com os ganhos médios diários para cada raça de acordo com o sistema de terminação empregado. A gordura visceral acumulada representa um desperdício que não agrega valor ao peso da carcaça, porém afeta a eficiência do animal em converter alimento, sendo inevitável o seu acúmulo quando o animal avança no grau de terminação (Di MARCO et al., 2007). 
Rev. Bras. Saúde Prod. Anim., Salvador, v.14, n.1, p.209-223 jan./mar., 2013 http://www.rbspa.ufba.br ISSN 15199940

Tabela 5.Médias e erro padrão (EP) das gorduras renal, de toalette, da mesentérica, do coração e do fígado, expressos em peso absoluto (PA) e em percentual de peso de corpo vazio (\%PCV), de acordo com o sistema de alimentação e o grupo genético avaliado

\begin{tabular}{|c|c|c|c|c|c|c|c|c|}
\hline \multirow{2}{*}{$\begin{array}{l}\text { Grupo } \\
\text { genético }\end{array}$} & \multicolumn{2}{|c|}{ Sistema de terminação } & \multirow{2}{*}{ Média } & \multirow{2}{*}{$\mathrm{EP}$} & \multicolumn{2}{|c|}{ Sistema de terminação } & \multirow{2}{*}{ Média } & \multirow{2}{*}{$\mathrm{EP}$} \\
\hline & Pastejo & Confinamento & & & Pastejo & Confinamento & & \\
\hline & \multicolumn{2}{|c|}{ Gordura Renal (kg) } & \multicolumn{6}{|c|}{ Gordura Renal (\%PCV) } \\
\hline Hereford & 3,22 & 2,80 & 3,01 & 1,4 & 0,84 & 0,73 & 0,78 & 0,04 \\
\hline Brangus & 2,21 & 3,72 & 2,97 & 1,0 & 0,57 & 0,96 & 0,76 & 0,04 \\
\hline Brahman & 2,38 & 2,70 & 2,70 & 1,1 & 0,63 & 0,76 & 0,69 & 0,05 \\
\hline Média & 2,61 & 3,18 & - & - & 0,68 & 0,82 & - & - \\
\hline \multirow[t]{2}{*}{$\mathrm{EP}$} & 1,6 & 1,4 & - & - & 0,06 & 0,06 & - & - \\
\hline & \multicolumn{2}{|c|}{ Gordura Toalete (kg) } & \multicolumn{6}{|c|}{ Gordura Toalete (\% PCV) } \\
\hline Hereford & $8,41^{\mathrm{a}}$ & 8,35 & 8,38 & 2,0 & $2,17^{\mathrm{a}}$ & 2,16 & 2,16 & 1,30 \\
\hline Brangus & $5,41^{\mathrm{bB}}$ & $9,00^{\mathrm{A}}$ & 7,20 & 2,1 & $1,40^{\mathrm{bB}}$ & $1,85^{\mathrm{A}}$ & 1,85 & 0,98 \\
\hline Brahman & $6,70^{\mathrm{bB}}$ & $8,54^{\mathrm{A}}$ & 7,62 & 1,5 & $1,75^{\mathrm{b}}$ & 1,95 & 1,95 & 1,25 \\
\hline Média & 6,84 & 8,63 & - & - & 1,77 & 2,21 & - & - \\
\hline \multirow[t]{2}{*}{$\mathrm{EP}$} & 2,41 & 2,23 & - & - & 2,03 & 2,1 & - & - \\
\hline & \multicolumn{2}{|c|}{$\begin{array}{c}\text { Gordura Mesentérica } \\
(\mathrm{k}) \mathrm{g}\end{array}$} & \multicolumn{6}{|c|}{$\begin{array}{c}\text { Gordura Mesentérica } \\
(\% \mathrm{PCV})\end{array}$} \\
\hline Hereford & $8,31^{\mathrm{a}}$ & $8,50^{\mathrm{a}}$ & 8,41 & 2,1 & $2,16^{\mathrm{a}}$ & $2,27^{\mathrm{a}}$ & 2,22 & 1,24 \\
\hline Brangus & $4,85^{\mathrm{bB}}$ & $8,87^{\mathrm{aA}}$ & 6,91 & 2,4 & $1,24^{\mathrm{bB}}$ & $2,28^{\mathrm{aA}}$ & 1,76 & 1,43 \\
\hline Brahman & $7,93^{\mathrm{a}}$ & $6,18^{\mathrm{b}}$ & 7,05 & 2,4 & $2,25^{\mathrm{a}}$ & $1,56^{\mathrm{b}}$ & 1,91 & 1,11 \\
\hline Média & 7,06 & 7,89 & - & - & 1,88 & 2,04 & - & - \\
\hline \multirow[t]{2}{*}{$\mathrm{EP}$} & 3,01 & 3,25 & - & - & 1,10 & 1,15 & - & - \\
\hline & \multicolumn{2}{|c|}{ Gordura Coração (kg) } & \multicolumn{6}{|c|}{ Gordura Coração (\%PCV) } \\
\hline Hereford & 0,20 & 0,19 & 0,19 & 0,08 & 0,05 & 0,05 & 0,05 & 0,003 \\
\hline Brangus & 0,20 & 0,33 & 0,27 & 0,07 & 0,05 & 0,09 & 0,07 & 0,003 \\
\hline Brahman & 0,23 & 0,23 & 0,23 & 0,08 & 0,06 & 0,06 & 0,06 & 0,002 \\
\hline Média & 0,24 & 0,25 & - & - & 0,05 & 0,07 & - & - \\
\hline \multirow[t]{2}{*}{$\mathrm{EP}$} & 0,08 & 0,05 & - & - & 0,03 & 0,02 & - & - \\
\hline & \multicolumn{2}{|c|}{ Gordura Fígado (kg) } & \multicolumn{6}{|c|}{ Gordura Fígado (\%PCV) } \\
\hline Hereford & 0,24 & 0,22 & 0,23 & 0,07 & 0,06 & 0,05 & 0,05 & 0,01 \\
\hline Brangus & 0,18 & 0,24 & 0,21 & 0,08 & 0,05 & 0,09 & 0,07 & 0,01 \\
\hline Brahman & 0,25 & 0,28 & 0,26 & 0,08 & 0,06 & 0,06 & 0,06 & 0,02 \\
\hline Media & 0,22 & 0,24 & - & - & 0,05 & 0,07 & - & - \\
\hline $\mathrm{EP}$ & 0,05 & 0,05 & - & - & 0,03 & 0,05 & - & - \\
\hline
\end{tabular}

Suplemento: milho (30\%), subproduto da limpeza de silo de soja $(69,5 \%)$ e sal mineral $(0,5 \%)$ oferecido na quantidade de $1 \%$ peso vivo.

${ }_{\text {a,b,c }}$ Médias seguidas por letras minúsculas diferentes na coluna, para a mesma característica, diferem $(\mathrm{p}<0,05)$ pelo teste de Tukey.

${ }_{\mathrm{A}, \mathrm{B}}$ Médias seguidas por letras maiúsculas diferentes na linha, para a mesma característica diferem $(\mathrm{p}<0,05)$ pelo teste de $\mathrm{t}$.

$\mathrm{EP}=$ erro padrão da media. 
Rev. Bras. Saúde Prod. Anim., Salvador, v.14, n.1, p.209-223 jan./mar., 2013 http://www.rbspa.ufba.br ISSN 15199940

Tabela 6. Médias e erro padrão (EP) dos pesos vazios do rúmen+retículo, omaso, abomaso e intestino, expressos em peso absoluto (PA) e em percentual de peso de corpo vazio (\% PCV), de acordo com o sistema de alimentação e o grupo genético avaliado

\begin{tabular}{|c|c|c|c|c|c|c|c|c|}
\hline \multirow{2}{*}{$\begin{array}{l}\text { Grupo } \\
\text { genético }\end{array}$} & \multicolumn{2}{|c|}{ Sistema de terminação } & \multirow{2}{*}{ Média } & \multirow{2}{*}{$\mathrm{EP}$} & \multicolumn{2}{|c|}{ Sistema de terminação } & \multirow{2}{*}{ Média } & \multirow{2}{*}{$\mathrm{EP}$} \\
\hline & Pastejo & Confinamento & & & Pastejo & Confinamento & & \\
\hline & \multicolumn{2}{|c|}{$\begin{array}{c}\text { Rúmen + Retículo vazios } \\
(\mathrm{kg})\end{array}$} & \multicolumn{6}{|c|}{$\begin{array}{c}\text { Rúmen + Retículo vazios } \\
(\% \mathrm{PCV})\end{array}$} \\
\hline Hereford & 7,13 & 7,14 & $7,13^{\mathrm{b}}$ & 2,40 & 1,83 & $1,84^{\mathrm{b}}$ & 1,84 & 1,10 \\
\hline Brangus & 7,40 & 8,23 & $7,81^{\mathrm{a}}$ & 2,25 & $1,88^{\mathrm{B}}$ & $2,11^{\mathrm{aA}}$ & 2,00 & 1,11 \\
\hline Brahman & 7,04 & 7,24 & $7,14^{\mathrm{b}}$ & 1,98 & 1,85 & $1,83^{\mathrm{b}}$ & 1,85 & 0,90 \\
\hline Média & 7,19 & 7,54 & - & - & 1,85 & 1,93 & - & - \\
\hline \multirow[t]{2}{*}{ EP } & 3,0 & 3,1 & - & - & 0,92 & 1,0 & - & - \\
\hline & \multicolumn{2}{|c|}{ Omaso vazio $(\mathrm{kg})$} & \multicolumn{6}{|c|}{ Omaso vazio (\%PCV) } \\
\hline Hereford & 2,74 & 3,10 & 2,92 & 1,35 & 0,72 & 0,84 & 0,78 & 0,09 \\
\hline Brangus & 1,22 & 3,13 & 2,17 & 1,33 & 0,52 & 0,81 & 0,57 & 0,08 \\
\hline Brahman & 2,26 & 2,44 & 2,36 & 1,40 & 0,60 & 0,63 & 0,61 & 0,10 \\
\hline Média & 2,07 & 2,89 & - & - & $0,54^{\mathrm{B}}$ & $0,76^{\mathrm{A}}$ & - & - \\
\hline \multirow[t]{2}{*}{$\mathrm{EP}$} & 1,50 & 1,65 & - & - & 0,5 & 0,8 & - & - \\
\hline & \multicolumn{2}{|c|}{ Abomaso vazio (kg) } & \multicolumn{6}{|c|}{ Abomaso vazio (\%PCV) } \\
\hline Hereford & 1,41 & 1,28 & 1,37 & 0,95 & 0,54 & 0,43 & 0,48 & 0,05 \\
\hline Brangus & 1,18 & 1,06 & 1,12 & 0,09 & 0,47 & 0,33 & 0,40 & 0,05 \\
\hline Brahman & 1,26 & 0,98 & 1,12 & 0,10 & 0,42 & 0,30 & 0,35 & 0,08 \\
\hline Média & $1,30^{\mathrm{A}}$ & $1,11^{\mathrm{B}}$ & - & - & $0,47^{\mathrm{A}}$ & $0,35^{\mathrm{B}}$ & - & - \\
\hline \multirow[t]{2}{*}{$\mathrm{EP}$} & 1,10 & 1,15 & - & - & 0,35 & 0,30 & - & - \\
\hline & \multicolumn{2}{|c|}{ Intestinos vazios (kg) } & \multicolumn{6}{|c|}{ Intestinos vazios (\%PCV) } \\
\hline Hereford & 7,56 & 6,70 & $7,13^{\mathrm{a}}$ & 3,00 & 1,94 & 1,74 & $1,84^{\mathrm{a}}$ & 1,10 \\
\hline Brangus & 5,53 & 6,04 & $5,78^{\mathrm{ab}}$ & 3,25 & 1,40 & 1,54 & $1,47^{\mathrm{ab}}$ & 1,22 \\
\hline Brahman & 5,23 & 4,14 & $4,69^{\mathrm{b}}$ & 2,28 & 1,35 & 1,06 & $1,20^{\mathrm{b}}$ & 1,00 \\
\hline Média & 6,10 & 5,62 & - & - & 1,56 & 1,45 & - & - \\
\hline EP & 2,10 & 2,11 & - & - & 0,9 & 0,8 & - & - \\
\hline
\end{tabular}

Suplemento: milho (30\%), subproduto da limpeza de silo de soja $(69,5 \%)$ e sal mineral $(0,5 \%)$ oferecido na quantidade de $1 \%$ peso vivo

a,b,c Médias seguidas por letras minúsculas diferentes na coluna, para a mesma característica, diferem $(\mathrm{p}<0,05)$ pelo teste de Tukey

${ }_{\mathrm{A}, \mathrm{B}}$ Médias seguidas por letras maiúsculas diferentes na linha, para a mesma característica diferem $(\mathrm{p}<0,05)$ pelo teste de $\mathrm{t}$

$\mathrm{EP}=$ erro padrão da media

O rúmen-retículo, quando avaliado em peso absoluto, não apresentou interação significativa $(\mathrm{P}>0,05)$ entre o grupo genético e sistema de terminação, observando-se os maiores pesos para o Brangus. Porém quanto os pesos de rúmen-retículo foram expressos em
\%PCV houve interação entre o grupo genético e o sistema de terminação, com superioridade do Brangus terminado em confinamento. Estes valores de rúmenretículo são inferiores aos apresentados por Hersom et al. (2004), que não observaram diferenças significativas 
Rev. Bras. Saúde Prod. Anim., Salvador, v.14, n.1, p.209-223 jan./mar., 2013 http://www.rbspa.ufba.br ISSN 15199940

entre novilhos Angus e Angus-Hereford com altos e baixos ganhos médios diários na terminação.

O maior tamanho dos intestinos nos animais em pastejo poderia ter sido causado pelo maior consumo de material fibroso do que aos animais em confinamento sendo os dados obtidos neste trabalho, em média, inferiores aos encontrados por Pacheco et al. (2005) em novilhos jovens e superjovens $5 / 8$ Charolês (CH) 3/8 Nelore (NE) e 5/8NE $3 / 8 \mathrm{CH}$ terminados em confinamento, Restle et al. (2005) em novilhos 5/8 Nelore 3/8 Charolês terminados em confinamento e abatidos com 425, 467 e $510 \mathrm{~kg}$, e Kuss et al. (2008) em novilhos $1 / 2$ Purunã $(1 / 2$ Angus $+1 / 4$ Charolês $+1 / 4$ Caracu $+1 / 4$ Canchim) $+1 / 2$ Canchim terminados em confinamento. Hersom et al. (2004) detalharam pesos superiores para rúmen-retículo $(2,4 \%)$, omaso vazio $(1,0 \%)$, intestinos $(2,0 \%)$ e levemente inferiores para o abomaso $(0,35 \%)$ novilhos Angus e Angus-Hereford com diferentes ganhos médios diários na terminação. $\mathrm{O}$ rúmen-retículo e os intestinos foram comparativamente menores no Brahman $(\mathrm{P}<0,05)$, corroborando com Solis et al. (1988), que encontraram que o Brahman apresentou um trato digestivo menor em \%PCV quando comparado com raças britânicas, associado a consumos comparativamente menores em \%PCV do animal.

O sistema de terminação de novilhos em pastagem com suplementação ou em confinamento não influenciaram 0 rendimento de corpo vazio dos componentes não-integrantes da carcaça.

Os novilhos Brahman apresentam maior peso de pele e menores pesos de coração, pulmão e baço que os Hereford e Brangus em PA e \%PCV, independente do sistema de terminação empregado.

\section{REFERÊNCIAS}

CALEGARE, L.; ALENCAR, M.M.; PACKER, I.U.; LANNA, D.P. Energy requirements and cow/calf efficiency of Nellore and Continental and British Bos taurus x Nellore crosses. Journal of Animal Science, v.85, n.10, p.2413-22, 2007.

CATTELAM, J.; FREITAS, L.S.; BRONDANI, I.L.; SILVA, J.H..S.; ARBOITTE, M.Z.; WEISE, M.S. Características dos componentes externos e das gorduras descartadas de novilhos superprecoces não castrados ou castrados de dois genótipos terminados em confinamento. Revista Brasileira de Zootecnia, v.40, n.8, p.1774-1780, 2011.

CHIZZOTTI, M.L.; VALADARES

FILHO, S.C.; TEDESCHI, L.O.; CHIZZOTTI, F.H.; CARSTENS, G.E. Energy and protein requirements for growth and maintenance of F1 Nellore $x$ Red Angus bulls, steers, and heifers.

Journal of Animal Science, v.85, n.8, p.1971-1981, 2007.

CNCPS. The net carbohydrate and protein system for evaluating herd nutrition and nutrient excretion, Model Documentation. Version 5.0. Cornell: Cornell University, 2003. 292p.

\section{CUMBY, J. Visceral organ}

development during restriction and realimentation. In: COURSE IN RUMINANT DIGESTION AND METABOLISM - ANSC6260, 2000, Guelph. Proceedings... Guelph: University of Guelph, 2000. p.23-29.

Di MARCO, O.N.; BARCELLOS, J.O.J.; COSTA, E.C. Crescimento de bovinos de corte. Porto Alegre: Universidade Federal do Rio Grande do Sul, 2007. 276p. 
Rev. Bras. Saúde Prod. Anim., Salvador, v.14, n.1, p.209-223 jan./mar., 2013 http://www.rbspa.ufba.br ISSN 15199940

EGGERT, D.L.; NIELSEN, M.K.

Comparison of feed costs of maintenance, lean deposition, and fat deposition in three lines of mice selected for heat loss. Journal of Animal Science, v.84, n.2, p.276-282, 2006.

FERREL, C.L.; JENKINS, T.G. Body composition and energy utilization by steers of diverse genotypes fed a highconcentrate diet during the finishing period: I: Angus, Belgian Blue, Hereford, and Piedmontese sires. Journal of Animal Science, v.76, n.2, p.637-646, 1998.

HERSOM, M.J.; KREHBIEL, C.R.; HORN, G.W. Effect of live weight gain of steers during winter grazing: II Visceral organ mass, cellularity, and oxygen consumption. Journal of Animal Science, v.82, n.1, p.184 -197, 2004.

KUSS, F.; BARCELLOS, J.O.J.; LOPEZ, J.; RESTLE, J.; MOLETTA, J.L.; PEROTTO, D. Componentes não integrantes da carcaça de novilhos não castrados ou castrados terminados em confinamento e abatidos aos 16 ou 26 meses de idade. Revista Brasileira de Zootecnia, v.37, n.10, p.1829-1836, 2008.

MACITELLI, F.; BERCHIELLI, T.T.; SILVEIRA, R.N.; ANDRADE, P.; LOPES, A. D.; BARBOSA, J.C.

Biometria da carcaça e peso de vísceras e de órgãos internos de bovinos mestiços alimentados com diferentes volumosos e fontes protéicas. Revista Brasileira de Zootecnia, v.34, n.5, p.1751-1762, 2005.

McBRIDE, B.W.; KELLY, J.M. Energy cost of absorption and metabolism in the ruminant gastrointestinal tract and liver: a review. Journal of Animal Science, v. 68, n.9, p.2997-3010, 1990.
MENEZES, L.F.G.; BRONDANI, I.L.; RESTLE, J.; ALVES FILHO, D.C.; CALLEGARO, A.M.; WEISE, M. Características dos componentes não integrantes da carcaça de novilhos superjovens da raça Devon, terminados em diferentes sistemas de alimentação. Arquivo Brasileiro de Medicina Veterinária e Zootecnia, v.63, n.2, p.372-381, 2011.

OWENS, F.N.; DUBESKI, P.; HANSON, C.F. Factors that alter the growth and development of ruminants. Journal of Animal Science, v.71, n.11, p.3138-3150, 1993.

PACHECO, P.S.; RESTLE, J.; SILVA, J.H.S.; BRONDANI, I.L.; PASCOAL, L.L.; ALVES FILHO, D.C.; ARBOITTE, M.Z.; FREITAS, A.K. Características das partes do corpo nãointegrantes da carcaça de novilhos jovens e superjovens de diferentes grupos genéticos. Revista Brasileira de Zootecnia, v.34, n.5, p.1678-1690, 2005.

RENNÓ, L.N.; VALADARES FILHO, S.C.; VALADARES, R.F.D.; CECON, P.R.; BACKES, A.A.; RENNÓ, F.P.; ALVES, D.D.; SILVA, P.A. Níveis de ureia na ração de novilhos de quatro grupos genéticos: consumo e digestibilidades totais. Revista Brasileira de Zootecnia, v.34, n.5, p.1775-1785, 2005.

RESTLE, J.; MENEZES, L.F.G.; ARBOITTE, M. .; PASCOAL, L.L.; PACHECO, P.S.; PÁDUA, J.T. Características das partes nãointegrantes da carcaça de novilhos 5/8Nelore 3/8Charolês abatidos em três estádios de desenvolvimento. Revista Brasileira de Zootecnia, v.34, n.4, p.1339-1348, 2005. 
Rev. Bras. Saúde Prod. Anim., Salvador, v.14, n.1, p.209-223 jan./mar., 2013 http://www.rbspa.ufba.br ISSN 15199940

RIBEIRO, T.R.; PEREIRA, J.C.; LEÃO, M.I.; OLIVEIRA, M.V.M.; QUEIROZ, A.C.; CECON, P.R.; MELO, R.C.A. Tamanho dos órgãos e vísceras de bezerros holandeses, para produção de vitelos, recebendo dietas com diferentes níveis de concentrado.

Revista Brasileira de Zootecnia, v.30, n.6, p.2163-2168, 2001. Supl.

SAS Institute. SAS/STAT: guide for personal computer. Version 9.1. Cary, 2003. 235p.

SANTOS, A.P.; BRONDANI, I.L.; RESTLE, J.; ALVES FILHO, D.C.; MENEZES, L. F.G.; PEIXOTO, L.A.O.; FERREIRA, J.J.; HECK, I. Influencia do grupo genético e a dieta alimentar no peso do corpo vazio e trato gastrointestinal de novilhos superprecoces. In: REUNIÃO ANUAL DA SOCIEDADE BRASILEIRA DE ZOOTECNIA, 40., 2003, Santa Maria. Anais.... Santa Maria: Sociedade Brasileira de Zootecnia, 2003a.

SANTOS, A.P.; RESTLE, J.; PASCOAL, L.L.; ALVES FILHO, D.C.; MENEZES, L.F.G.; PEIXOTO, L.A.O.; FERREIRA, J.J.; HECK, I. Influência do grupo genético e a dieta alimentar no peso do corpo vazio e órgãos vitais de novilhos superprecoce. In: REUNIÃO ANUAL DA SOCIEDADE BRASILEIRA DE ZOOTECNIA, 40., 2003, Santa Maria. Anais.... Santa Maria: Sociedade Brasileira de Zootecnia, 2003b.
SOLIS, J.C.; BYERS, F.M.;

SCHELLING, G.T.; LONG, C.R.;

GREENE, L.W. Maintenance

requirements and energetic efficiency of cows of different breed types. Journal

of Animal Science, v.66, n.3, p.764773, 1988.

TEDESCHI, L.O.; BOIN, C.; FOX, D.G. Energy requirements for maintenance and growth of Nellore bulls and steers fed high-forage diets.

Journal of Animal Science, v.80, n.6, p.1671-1682, 2002.

VALADARES FILHO, S.C.; CHIZZOTI, M.L.; PAULINO, P.V. Exigências nutricionais de bovinos de corte no Brasil: desafios. Revista

Ceres, v.56, n.4, p.448-495, 2009.

VÉRAS, A.S.C.; VALADARES FILHO, S.C.; SILVA, J.F.C.; PAULINO, M.F.; CECON, P.R.; VALADARES, R.F.D.; FERREIRA, M.A.; FONTES, C.M.S. Efeito do nível de concentrado sobre o peso dos órgãos internos e do conteúdo gastrintestinal de bovinos Nelore não-castrados. Revista

Brasileira de Zootecnia, v.30, n.3, p.1120-1126, 2001.

Data de recebimento: 04/12/2012

Data de aprovação: 25/03/2013 